\title{
Biologia e tabela de vida de fertilidade de Diabrotica speciosa (Col.: Chrysomelidae) em dieta natural
}

\section{Biology and fertility life table of Diabrotica speciosa (Col.: Chrysomelidae) in natural diet}

\author{
Jefferson Silveira Teodoro ${ }^{*}$, Calisc de Oliveira Trecha ${ }^{2}$, Lauren Bittencourt Medina ${ }^{2}$, \\ Letícia Hellwig², Carolini Vaz de Lima², Ana Paula Schneid Afonso da Rosa ${ }^{2}$
}

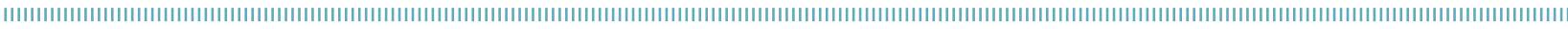

RESUMO: A vaquinha Diabrotica speciosa é uma importante praga em diversas culturas. O objetivo deste trabalho foi estudar a biologia de adultos de D. speciosa e construir a tabela de vida de fertilidade em dieta natural à base de feijáo, e à base de feijáo, rodelas de cenoura e solução de mel a $10 \%$. Os parâmetros biológicos avaliados foram: duração dos períodos de pré-oviposição, oviposição e pós-oviposiçáo, fecundidade total, longevidade de adultos e viabilidade dos ovos. Para a tabela de vida de fertilidade, os parâmetros determinados foram: intervalo entre geraçôes $(T)$, taxa líquida de reprodução (Ro), taxa intrínseca de crescimento $(\mathrm{rm})$ e taxa finita de aumento $(\lambda)$. A partir dos resultados obtidos, pode-se constatar que houve influência do alimento oferecido aos adultos para os períodos de pré-oviposição e oviposição, e também na fecundidade total e na viabilidade dos ovos. A longevidade dos adultos foi influenciada pela dieta constituída de folíolos de feijão. A dieta constituída de feijão, cenoura e mel propiciou maior longevidade significativa dos machos em relaçáo àqueles alimentados com feijão. Os resultados da tabela de fertilidade indicaram que o potencial de reprodução de $D$. speciosa aumenta significativamente em duas geraçôes sucessivas quando as fêmeas são alimentadas com feijão, cenoura e mel, demonstrando que há melhoria na criação massal desse inseto em condiçóes de laboratório.

PALAVRAS-CHAVE: vaquinha; taxa de reprodução; hospedeiros.

\begin{abstract}
Corn rootworm Diabrotica speciosa is an important pest in several crops. The aim of this work was to study the biology of adult D. speciosa and build a fertility life table in the natural diet based on beans, and beans, sliced carrots and honey solution at $10 \%$. The following parameters were: duration of pre-oviposition, oviposition and post-oviposition, total fertility, adult longevity and egg viability. For the fertility life table parameters, the following were determined: generation interval $(\mathrm{T})$, net reproductive rate $(\mathrm{Ro})$, intrinsic rate of increase $(\mathrm{rm})$ and finite rate of increase $(\lambda)$. From the results obtained, it can be observed that there was an influence of food offered to adults for the duration of pre-oviposition and oviposition, and also in total fertility and viability of eggs. Adult longevity was influenced by diet consisting of bean leaflets. Among the treatments, a diet consisting of beans, carrot and honey provided higher significant longevity of males compared to those fed with beans. The results in the fertility table indicated that the reproductive potential of $D$. speciosa significantly increases in two successive generations when females are fed on beans, carrots and honey, showing there is improved mass rearing for this insect under laboratory conditions.
\end{abstract}

KEYWORDS: corn rootworm; reproduction rate; host plant. 


\section{INTRODUÇÃO}

Diabrotica speciosa (Germar, 1824) é um coleóptero fitófago, com ocorrência em todo o Brasil e em alguns países da América do Sul. Tem grande importância para a agricultura pelo seu hábito polífago em alimentos de elevado valor econômico, como leguminosas, gramíneas, solanáceas e cucurbitáceas (Pecchioni et al., 2000; Milanez et al., 2001).

Os adultos alimentam-se da parte aérea das plantas, tais como: flores, folhas e frutas, enquanto as larvas perfuram as raízes e os tubérculos das plantas (GaSsen, 1989). Além dos danos diretos causados pelo seu hábito alimentar, são conhecidos como vetor de viroses e doenças bacterianas para diversas espécies de plantas (BofF; Gandin, 1992, Oliveira et al., 1994; WaLSH, 2003).

De modo a fornecer subsídios necessários para o manejo eficiente de uma praga, a manutençáo de colônias de insetos em laboratório é indispensável, tanto nas pesquisas básicas como nas aplicadas, exigindo um suprimento grande de insetos (PARRa, 2001). Assim, informações dos processos ecológicos, fisiológicos e comportamentais demonstrados pelos insetos são fundamentais, pois estáo ligados ao contexto nutricional. Devido a isso, é de extrema importância conhecer a preferência e os hábitos alimentares, assim como as necessidades nutricionais dos insetos e suas consequências no crescimento, sobrevivência, longevidade, reprodução, movimentos e hábitos gregários (Panizzi; Parra, 2009).

De acordo com TAuber; TAuber (1974), a dieta ingerida por um inseto pode influenciar seu estado interno, refletindo em sua atividade externa. As substâncias químicas necessárias para a realização das funçôes biológicas dos insetos vêm do alimento consumido por eles. Na literatura, existem vários registros de estudos em laboratório relacionados às técnicas de criação e bioecologia de D. speciosa (Haji, 1981; Pecchioni, 1988; Silva-WernecK et al., 1995; Ávila et al., 2000; Milanez; Parra, 2000; Ávila; Parra, 2002; Bitencourt, 2007).

A criação de $D$. speciosa em laboratório tem como objetivo fornecer ovos, larvas e adultos que são necessários para as pesquisas direcionadas ao aperfeiçoamento e ao desenvolvimento de táticas para o seu controle, bem como a avaliação de modificaçôes introduzidas em técnicas de criação conhecidas, sempre com o intuito de disponibilizar novas opçôes (Ávila; Parra, 2002).

Da mesma forma, Coppel; Mertins (1977) relataram que o estudo da tabela de vida de fertilidade é de grande valia para a compreensão da dinâmica populacional de uma espécie, uma vez que permite uma visão integrada das características biológicas de uma população, sob condiçōes ambientais determinadas. Assim, o objetivo deste trabalho é determinar a influência do alimento oferecido na fase adulta de D. speciosa sobre o desenvolvimento, a capacidade reprodutiva e a longevidade, bem como avaliar os parâmetros da tabela de vida de fertilidade dessa espécie.

\section{MATERIAIS E MÉTODOS}

O experimento foi realizado durante o mês de março de 2012, no Núcleo de Manejo Integrado de Pragas (NUMIP), da Embrapa Clima Temperado, localizado no município do Capão-do-Leão, no estado do Rio Grande do Sul.

Para o fornecimento dos adultos de D. speciosa, obtidos pelo método de criação descrito por Ávila et al. (2000), larvas recém-eclodidas foram infestadas por meio de um pincel de cerdas finas, em seedlings de milho orgânico (Zea mays L.), mantidos em vermiculita expandida esterilizada em recipientes plásticos (20 cm de diâmetro x $10 \mathrm{~cm}$ de altura). Treze dias após a inoculaçáo, as larvas foram transferidas, por peneiramento, dos recipientes de infestaçấo para um segundo recipiente plástico, contendo vermiculita e novas plântulas de milho (provenientes da mesma metodologia), onde foram mantidas até atingirem a fase pupal.

Os adultos recém-emergidos foram separados por sexo conforme White (1977). Os casais formados, com o mesmo tempo de vida, foram acondicionados em gaiolas plásticas transparentes ( $13 \mathrm{~cm}$ de altura $\times 8 \mathrm{~cm} \times 6 \mathrm{~cm}$ de base e topo) desprovidas de fundo, o qual foi substituído por tecido tipo voil, para permitir a areaçáo, fixado com atilho de borracha. Em cada gaiola colocou-se um casal de D. speciosa.

Para a determinaçáo da influência do alimento consumido na fase adulta de D. speciosa, foram utilizados dois tratamentos. No primeiro ensaio, os insetos foram alimentados com dois folíolos de feijão, e, no segundo, foram oferecidos dois folíolos de feijáo, uma rodela de cenoura $(1 \mathrm{~cm}$ de largura $\mathrm{x}$ $2 \mathrm{~cm}$ diâmetro) (Daucus carota L.) e solução de mel a 10\%.

Os folíolos de feijāo foram mantidos em pequenos frascos de vidro de $4 \mathrm{~mL}$, com água destilada, as rodelas de cenoura, em placas de Petri, e a soluçáo de mel a $10 \%$, fornecida em frascos plásticos de $4 \mathrm{~mL}$ com algodáo hidrófilo, todos colocados no interior da gaiola plástica transparente. Também colocou-se no interior da gaiola uma gaze de coloração preta, umedecida com água destilada, como substrato de oviposiçấo. Para os adultos alimentados somente com feijão a mesma metodologia foi utilizada. $\mathrm{O}$ alimento foi trocado a cada quatro dias. A gaiola, o alimento e o substrato de oviposiçáo foram colocados sobre um prato plástico forrado com papel filtro.

Os ensaios foram conduzidos em delineamento inteiramente casualizado com dois tratamentos (feijão e feijão + cenoura + solução de mel), sem diferença de tempo entre eles, e com 20 repetiçóes, os quais foram acondicionados em sala climatizada, à temperatura de $25 \pm 2^{\circ} \mathrm{C}, \mathrm{UR}, 60 \pm 10 \%$ e fotofase de 14 horas.

O número de ovos em cada gaiola também foi verificado a cada quatro dias, sendo que a segunda postura foi separada, conforme Ávila et al. (2000), para a determinação da viabilidade dos ovos.

Avaliaram-se o período de pré-oviposição (tempo estabelecido entre a emergência da fêmea e o início da postura), 
a fecundidade (número de ovos/fêmea) total e média, o período de oviposição (período de postura dos ovos) e a longevidade de machos e fêmeas em cada tratamento.

A partir dos dados de sobrevivência e oviposição, foram elaboradas tabelas de vida de fertilidade (Silveira Neto et al., 1976). Posteriormente, calcularam-se o número médio de ovos por fêmea $(\mathrm{mx})$ em cada data de oviposição $(\mathrm{x})$, considerando o total de fêmeas, o índice de sobrevivência acumulado de fêmeas (lx) durante o período de oviposição, e o número de descendentes que atingiram a idade $\mathrm{x}$. Estes valores constituíram as colunas das tabelas de vida.

Com base nas informaçóes condensadas na tabela de vida, estimaram-se os seguintes parâmetros para cada tratamento (MaiA et al., 2000): intervalo entre geraçóes (T), que representa o tempo médio entre a postura de ovos de uma geração e a postura da geração seguinte; taxa líquida de reprodução (Ro), que é a estimativa do número médio de fêmeas gerado por fêmea ao longo do período de oviposição e que chegarão à geração seguinte; taxa intrínseca de crescimento $(\mathrm{rm})$, que é o fator relacionado à velocidade de crescimento da população; e a taxa finita de aumento $(\lambda)$, que é o fator de multiplicação de crescimento diário da populaçáo.

Os dados dos parâmetros biológicos obtidos nos ensaios foram submetidos ao teste $\mathrm{t}$ através do programa GENES (Cruz, 2001) e, a fim de normalizar e reduzir a heterogeneidade das variaçōes, foram transformadas as variáveis período de pré-oviposiçáo, período de oviposição, fecundidade total e longevidade de macho e fêmea para $\sqrt{x+0,5}$. As médias foram comparadas por meio do teste de Tukey a $5 \%$ de significância.

Os espécimes utilizados neste experimento foram depositados na Coleção Entomológica da Embrapa Clima Temperado.

\section{RESULTADOS E DISCUSSÃO}

Com relação aos parâmetros biológicos dos adultos de $D$. speciosa, verificou-se que o período de pré-oviposição foi influenciado significativamente pela dieta oferecida aos adultos, constituída de folíolos de feijão, rodelas de cenoura e solução de mel a $10 \%$, em comparação aos insetos alimentados somente com folíolos de feijāo (Tabela 1). Esses resultados diferem dos obtidos por Bitencourt (2007), que observou duração média de 9,7 dias para o período de pré-oviposição para adultos alimentados com feijão. ÁvıLA et al. (2000) constataram um período de pré-oviposição de 10,2 dias em adultos alimentados com folíolos de feijão, semelhantes aos obtidos por Silva-Werneck et al. (1995) e Milanez (1995), que utilizaram as mesmas dietas na fase larval e adulta do inseto. Pecchioni et al. (2000), alimentando adultos de D. speciosa speciosa com folhas de alface, obtiveram um período de pré-oviposição de 23,1 dias. Essa diferença pode estar relacionada à idade fisiológica da planta hospedeira oferecida ao inseto, que pode influenciar o comportamento, a sobrevivência e a taxa de reprodução durante o processo de alimentaçáo (Bitencourt, 2007).

O período de oviposição também foi influenciado pelo alimento ingerido pelas fêmeas de D. speciosa (Tabela 1). Esses resultados foram superiores aos obtidos por SiLVA-WERNECK et al. (1995) (16,6 dias) e Milanez; Parra (1995), que obtiveram um período médio de oviposição de 8,7 dias quando os adultos foram criados sobre folhas de feijoeiro e larvas sobre dieta artificial. Já Milanez (1997) determinou um período de oviposiçáo de 40,2 dias, criando os adultos sobre folíolos de feijoeiro e larvas sobre radícula de milho germinado, resultado também similar ao encontrado por BitENCOURT (2007) em adultos alimentados com folíolos de feijão. Porém, Ávila et al. (2000) observaram um período de oviposição superior ao encontrado no presente estudo, de 61,1 dias, em média, para os adultos obtidos a partir de larvas criadas em dieta natural nos substrato vermiculita, e 65,0 dias no substrato papel.

Em relaçáo à fecundidade de D. speciosa, constatou-se maior valor para as fêmeas alimentadas com a dieta de feijão, cenoura e mel, diferindo significativamente da dieta somente à base de feijão (Tabela 1). Esses valores foram expressivamente superiores quando comparados aos obtidos por Pecchioni et al. (2000), que observaram 1441,75 ovos/fêmea alimentadas com alface; Ávila et al. (2000), 1724,1 ovos/ fêmea criadas com folíolos de feijão; SiLVA-Werneck et al. (1995) e Milanez (1995), que obtiveram 384,6 e 1011 ovos/fêmea, respectivamente, utilizando a mesma dieta nas fases larval e adulta de D. speciosa.

Ávila; Parra (2002), ao avaliarem o desenvolvimento de D. speciosa em diferentes hospedeiros, constataram que fêmeas

Tabela 1. Período (dias) de pré-oviposição \pm Erro Padrão, oviposição e fecundidade total de adultos de Diabrotica. speciosa alimentados com diferentes dietas em condições controladas.

\begin{tabular}{|c|c|c|c|}
\hline Tratamento & PPO & PO & Fecundidade total \\
\hline Feijão & $\begin{array}{c}27,1 \pm 1,66 a \\
{[14]}\end{array}$ & $\begin{array}{c}29,45 \pm 4,40 b \\
{[14]}\end{array}$ & $\begin{array}{c}3766,0 \pm 27,09 b \\
{[14]}\end{array}$ \\
\hline Feijão + Cenoura + Mel & $\begin{array}{c}19,1 \pm 1,84 b \\
{[19]}\end{array}$ & $\begin{array}{c}48,5 \pm 5,65 a \\
{[19]}\end{array}$ & $\begin{array}{c}6597,0 \pm 40,38 a \\
{[19]}\end{array}$ \\
\hline Média Geral & 23,1 & 38,97 & 5181,5 \\
\hline CV (\%) & 24,96 & 37,22 & 35,57 \\
\hline
\end{tabular}

Médias seguidas das mesmas letras na coluna não diferem entre si pelo teste de Tukey a $5 \%$ de significância; Valores entre colchetes expressam o número de observações; PPO: pré-oviposição; PO: oviposição. 
alimentadas com folhas de batata e de feijoeiro apresentaram capacidade de postura superior àquelas mantidas em folhas de soja ou milho, evidenciando a influência do alimento para a fecundidade.

Segundo WheEler (1996), a capacidade de postura dos insetos é determinada pela ovogênese, processo fisiológico regulado pela disponibilidade de nutrientes presentes no corpo da fêmea, que é dado pelo alimento ingerido, corroborando os resultados obtidos neste estudo.

Ávila; Parra (2002) relataram que a capacidade de postura de D. speciosa pode estar relacionada às diferenças na quantidade do nitrogênio foliar encontrada nos hospedeiros, o qual pode não estar todo disponível para ser utilizado pelos adultos. Para MatTson (1980), a concentraçáo e a disponibilidade de nitrogênio no tecido foliar para a nutrição do inseto é uma característica de cada espécie de planta hospedeira.

De acordo com Hamilton (1972), o uso de solução de água e mel comprova que a adição à dieta de folhas de Vicia faba em substituição ao pólen com mel fornecido aos adultos de Diabrotica undecimpunctata howardii determinou um acréscimo na produção de ovos por fêmea, quando comparado com a dieta exclusivamente com folhas de fava, o que foi constatado neste trabalho com os adultos que tiveram sua dieta à base de feijão, cenoura e mel.

Testes preliminares já tinham constatado que a utilizaçáo de cenoura, apesar de náo ser uma planta referida para D. speciosa como complemento da dieta dos adultos, determinou um significativo incremento na oviposiçáo das fêmeas. Ventura et al. (2001) também constataram êxito na criação de laboratório quando se fez uso de cenoura como alimento único para essa espécie. Porém, não há evidências anteriores a este trabalho na literatura sobre o real efeito da nutrição de D. speciosa alimentada com rodelas de cenoura. A utilização de outros alimentos para complementar as necessidades alimentares de crisomelídeos foi verificada também por Chalfant; Mitchell (1967), que, utilizando abóbora fresca na alimentação de adultos de $D$. undecimpunctata howardii, observaram aumento significativo no período de oviposiçáo.

Tzanakakis; Phillips (1969), usando dietas artificiais à base de folhas de alfafa e cenoura para a criação de Grapholita molesta, obtiveram pupas de fêmeas mais pesadas em relação às de machos. Esse fato também foi observado por LaING; Hagen (1970) para o mesmo inseto criado com dieta à base de cenoura.
Partindo da hipótese que uma pupa mais pesada originaria uma fêmea mais pesada e bem mais nutrida fisiologicamente, haveria maior probabilidade de desenvolvimento de uma ovogênese bem-sucedida, o que estaria ligado à utilizaçáo do alimento.

Dessa forma, qualquer fator que afete a assimilação de nutrientes pelo inseto poderá afetar a ovogênese e, consequentemente, a taxa de postura (Ávila; Parra, 2002). Panizzi; PARRA (2009) reforçaram que a funçáo principal do adulto está relacionada à reprodução e, em muitos casos, à dispersão. Essas funçôes são dependentes da interação e da integração de processos fisiológicos e comportamentais, os quais estáo intimamente correlacionados ao consumo e à utilizaçáo de alimento.

A longevidade de adultos machos foi afetada pelo tipo de alimento oferecido, ao passo que, para as fêmeas, não houve diferença significativa (Tabela 2). Com relação à longevidade entre indivíduos machos e fêmeas, para a mesma dieta oferecida houve diferença significativa apenas na alimentação à base de feijão (Tabela 2).

Esses resultados foram superiores aos encontrados por Silva-Werneck et al. (1995), Milanez (1997) e Bitencourt (2007), utilizando folíolos de feijão para a alimentação de adultos de D. speciosa. Ávila et al. (2000) não observaram influência do alimento na longevidade de machos e fêmeas dos insetos adultos provenientes de larvas criadas com dieta natural mantida em vermiculita e em papel, porém, houve diferença significativa quando foram utilizados adultos provenientes de sistema de criação em dieta artificial. De acordo com esses autores, essas diferenças podem ser atribuídas às distintas metodologias empregadas para criação ou manutenção dos insetos, embora o mesmo alimento tenha sido utilizado nas fases larval e adulta, assim como diferentes populaçóes de D. speciosa utilizadas.

LanCe; Fisher (1987) e Naranjo; Sawyer (1987) também verificaram que a fecundidade e a longevidade de Diabrotica barberi foram significativamente afetadas pelo tipo de dieta utilizada na fase adulta. Corroborando com Klemola et al. (2007), que relataram que a qualidade do alimento consumido por larvas herbívoras pode causar efeito direto sobre diferentes características do indivíduo, tais como fecundidade, crescimento, sobrevivência e função imune.

No que diz respeito à viabilidade dos ovos de D. speciosa, houve diferença significativa na porcentagem de larvas

Tabela 2. Longevidade (dias) de machos e fêmeas \pm Erro Padrão e viabilidade de ovos de adultos de Diabrotica speciosa alimentados com diferentes dietas em condições controladas.

\begin{tabular}{lccc} 
Tratamento & Longevidade macho & Longevidade fêmea & Viabilidade (\%) \\
Feijão & $56,0 \pm 1,42$ b B & $78,9 \pm 1,10$ a A & $70,4 \pm 9,30$ b \\
& {$[14]$} & {$[14]$} & {$[11]$} \\
Feijão + Cenoura + Mel & $82,5 \pm 6,84$ a A & $88,5 \pm 9,51$ a A & $85,6 \pm 1,54$ a \\
\hline Média Geral & {$[17]$} & {$[17]$} & {$[9]$} \\
\hline CV (\%) & 69,3 & 83,7 & 78 \\
\hline
\end{tabular}

Médias seguidas das mesmas letras, minúscula na coluna e maiúscula na linha, não diferem entre si pelo teste de Tukey a 5\% de significância; Valores entre colchetes expressam o número de observações. 
eclodidas entre os dois tratamentos avaliados (Tabela 2). Esses resultados foram maiores em relação aos observados por Bitencourt (2007), que, alimentando adultos de D. speciosa com feijão e outros hospedeiros, obteve uma viabilidade média de ovos de $21 \%$.

A duração média de uma geração (T) foi de 13,00 semanas para as dietas à base de feijão, cenoura e mel, e 13,23 semanas para os adultos alimentados somente com feijão. A taxa líquida de reprodução (Ro), a capacidade inata de aumentar em número $(\mathrm{rm})$ e a razão finita de aumento $(\lambda)$, ou seja, o número de fêmeas adicionadas à população que poderá gerar fêmeas, para $D$. speciosa com a dieta à base de feijão, cenoura e mel, foi de 83,$291 ; 1,17$ e 3,218, respectivamente, e para a base de feijão foi de 56,311; 0,99 e 2,695 (Tabela 3). Esses valores foram menores comparado com os de Pecchioni et al. (2000), que, alimentando adultos de D. speciosa speciosa com folhas de alface, encontraram duração média de uma geraçáo de 112 dias, com taxa de reprodução de 185,04.

Para o presente estudo, esses resultados indicam que, decorridos 91 dias (duração média da geração), podem-se esperar cerca de 80 fêmeas resultantes de cada fêmea alimentada com folíolos de feijão, rodelas de cenoura e solução de mel a 10\%, em fase de reprodução. Quando as fêmeas têm sua dieta à base de folíolos
Tabela 3. Taxa líquida de reprodução (Ro), duração média em semanas de uma geração $(T)$, capacidade inata de aumentar em número $(\mathrm{rm})$ e razão finita de aumento $(\lambda)$ de adultos de Diabrotica speciosa com diferentes dietas em condições controladas (CAPÃO-DO-LEÃO, 2012).

\begin{tabular}{lcccc} 
Tratamento & Ro & T & rm & $\lambda$ \\
\hline Feijão & 56,311 & 13,23 & 0,99 & 2,695 \\
\hline Feijão + Cenoura + Mel & 83,291 & 13,00 & 1,17 & 3,218 \\
\hline
\end{tabular}

de feijão, esse número cai para aproximadamente 55 fêmeas resultantes por fêmea, demonstrando o grande potencial de reprodução de D. speciosa com o incremento de outros alimentos em sua dieta, o que demonstra sua importância para a manutenção da criação e estudos efetuados em condiçôes de laboratório.

\section{CONCLUSÃO}

D. speciosa alimentada com dieta constituída de folíolos de feijão, rodelas de cenoura e solução de mel a $10 \%$ apresenta elevado potencial de reprodução, com uma ótima viabilidade de ovos e alta fecundidade, o que evidencia a importância da manutenção da criação em condiçôes de laboratório.

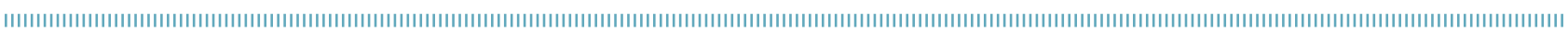

\section{REFERÊNCIAS}

ÁVILA, C.J.; PARRA, J.R.P. Desenvolvimento de Diabrotica speciosa (Germar) (Coleoptera: Chrysomelidae) em diferentes hospedeiros. Ciência Rural, Santa Maria, v.32, n.5, p.739-743, 2002.

ÁVILA, C.J., TABAI, A.C.P., PARRA, J.R.P. Comparação de técnicas para criação de Diabrotica speciosa (Germar) (Coleoptera: Chrysomelidae) em dietas natural e artificial. Anais da Sociedade Entomológica do Brasil, Londrina, v.29, n.2, p.257-267, 2000.

BITENCOURT, D.R. Biologia, capacidade reprodutiva e consumo foliar de Diabrotica speciosa (German, 1824) (Coleoptera: Chrysomelidae) em diferentes hospedeiros. 2007.48f. Dissertação(Mestrado)-Universidade Federal da Grande Dourados (UFGD), Dourados, MS, 2007.

BOFF, M.I.C.; GANDIN, C.L.G. Principais pragas na cultura da melancia e seu controle. Agropecuário Catarinense, Florianópolis, v.5, p.39-41, 1992.

CHALFANT, R.B.; MITCHELL, E.E. Some effects of food and substrate on oviposition of the spotted cucumber beetle. Journal of Economy Entomology, College Park, v.60, n.4, p.1010-1012, 1967.

COPPEL, H.C.; MERTINS, J.W. Biological insect pest suppression. New York: Springer-Verlag. 1977. 314p.

CRUZ, C.D. Programa Genes - Aplicativo computacional em genética e estatística. www.ufv.br/dbg/genes/genes.htm 2010. Acesso em: ago. 2012.
GASSEN, D.N. Insetos subterrâneos prejudiciais às culturas no sul do Brasil. Passo Fundo: Embrapa-CNPT. 1989. 49p. (EmbrapaCNPT. Documentos 13).

HAMILTON, E.W. Pollen substitute and honey and diet for Diabrotica. Journal of Economic Entomology, College Park, v.65, n.3, p.887, 1972.

HAJI, N.F.P. Biologia, dano e controle de adulto de Diabrotica speciosa (Germar, 1824) (Coleoptera: Chrysomelidae) na cultura da batatinha (Solanum tuberosum L.). 1981.53f. Tese (Doutorado) Escola Superior de Agricultura "Luiz de Queiroz", Universidade de São Paulo, Piracicaba, 1981.

KLEMOLA, N.; KLEMOLA T.; RANTALA, M.J.; RUUHOLA, T. Natural host-plant quality affects immune defence of an insect herbivore. Entomologia Experimentalis et Applicata, Dordrecht, v.123, n.2, p. 167-176, 2007.

LAING, D.R.; HAGEN, K.S. Axenic, partially synthetic diet for the oriental fruit moth, Grapholita molesta (Lepidoptera: Olethreutidae). The Canadian Entomologist, Ottawa, v.102, p.250-252, 1970.

LANCE, D.R., FISHER, J.R. Food quality of the various plant tissues for adults of the northern corn rootworm (Coleoptera: Chrysomelidae). Journal of the Kansas Entomological Society, Lawrence, v.60, n.3, p.462-466, 1987. 
MAIA, H.N.M.; LUIZ, A.J.B.; CAMPANHOLA, C. Statistical inference on associated fertility life table parameters using jackknife technique: computational aspects. Journal of Economic Entomology, Lanham, v.93, n.2, p.511-518, 2000.

MATTSON, W.J. Herbivory in relation to plant nitrogen content. Annual Review of Ecology and Systematics, Palo Alto, v. 11 , p. $119-161,1980$.

MILANEZ, J.M. Ciclo biológico da vaquinha, praga do milho na região Sul do país. Agropecuária Catarinense, Florianópolis, v. 10, n. 1, p.9-11, 1997.

MILANEZ, J.M.; PARRA, J.R.P. Biologia de Diabrotica speciosa (Germar, 1824) em dieta artificial. In: CONGRESSO BRASILEIRO DE ENTOMOLOGIA, 15., Caxambu, MG, 1995. Anais. Caxambu: SEB, 1995, p.54.

MILANEZ, J.M.; PARRA, J.R.P. Biologia e exigências térmicas de Diabrotica speciosa (Germar) (Coleoptera: Chrysomelidae) em laboratório. Anais da Sociedade Entomológica do Brasil, Londrina, v.29, n. 1, p.23-29, 2000.

MILANEZ, J.M.; CORTINA, J.V.; LAJUS, C.R.; MENEGUZZI, Z.; CHIARADIA, L.A. Estudos da altura de vôo e flutuação populacional de Diabrotica speciosa (Coleoptera: Chrysomelidae). In: REUNIÃO SUL BRASILEIRA DE PRAGAS DE SOLO, 8., 2001, Londrina, PR. Anais. Londrina: 2001. p.253-254.

NARANJO, S.E., SAWYER, A.J. Reproductive biology and survival of Diabrotica barberi (Coleoptera: Chrysomelidae): effect of temperature, food, and seasonal time of emergence. Annals of the Entomological Society of America, College Park, v.80, n.6, p.841-848, 1987.

OLIVEIRA, C.R.B.; MARINHO, V.L.A.; ASTOLFI, F.S.; AZEVEDO, M.; CHAGAS, C.M.; KITAJIMA, E.W. Purification, serology and some properties of the purple granadilla (Passiflora edulis) mosaic virus. Fitopatologia Brasileira, Brasília, v. 19, n.3, p.455-462, 1994.

PARRA, J.R.P. Técnicas de criação de insetos para programas de controle biológico. Piracicaba: ESALQ. 2001. 134p.

PANIZZI, A.R.; PARRA, J.R.P. (Ed.) Bioecologia e nutrição de insetos: base para o manejo integrado de pragas. 1 ed. Brasília: Embrapa/CNPq. 2009. 1164 p.
PECCHIONI, M.T.D. Crianza de Diabrotica speciosa (Coleoptera: Chrysomelidae) bajo condiciones de laboratorio. Revista Peruana de Entomologia, Lima, v.31, p.86-90, 1988.

PECCHIONI, M.T.D.; CABRERA, N.; LAGUZZI, S.M.; NOVARA, C.R. Aspectos Morfológicos y Poblacionales de Diabrotica speciosa speciosa (Germar) (Coleoptera: Chrysomelidae) en Condiciones de Laboratorio. Anais da Sociedade Entomológica do Brasil, Londrina, v.29, n.2, p.285-294, 2000.

SILVA-WERNECK, J.O., DE FARIA, M.R., ABREU NETO M.V.; MAGALHÃES, B.P.; SCHIMIDT, F.G.V. Técnica de criação de Diabrotica speciosa (Germ.) (Coleoptera: Chrysomelidae) para bioensaios com bacilos e fungos entomopatogênicos. Anais da Sociedade Entomológica do Brasil, Piracicaba, v.24, n.1, p.45-52, 1995.

SILVEIRA NETO, S.; NAKANO, O.; BARBIN, D.; VILA NOVA, N.A. Manual de ecologia de insetos. Piracicaba: Ceres, 1976. 419p.

TAUBER, M.J.; TAUBER, C.A. Dietary influence on reproduction in both sexes of five predacious species (Neuroptera). The Canadian Entomologist, Ottawa, v.106, n.9, p.921-5, 1974.

TZANAKAKIS, M.E.; PHILLIPS, J.H.H. Artificial diets for larvae of the Oriental Fruit Moth. Journal of Economic Entomology, Lanham, v.62, n.4, p.879-882, 1969.

VENTURA, M.U.; MELLO, E.P.; OLIVEIRA, A.R.M.; SIMONELLI, F.; MARQUES, F.A.; ZARBIN, P.H.G. Males are attracted by female traps: a new perspective for management of Diabrotica speciosa (Germar) (Coleoptera: Chrysomelidae) using sexual pheromone. Neotropical Entomology, Londrina, v.30, n.3, p.361-364, 2001.

WALSH, G.C. Host range and reproductive traits of Diabrotica speciosa (Germar) and Diabrotica viridula (F.) (Coleoptera: Chrysomelidae), two species of South America pest rootworms, with notes on other species of Diabroticina. Environmental Entomology, Lanham, v.32, n.2, p.276-285, 2003.

WHEELER, D. The role of nourishment in oogenesis. Annual Review of Entomology, Palo Alto, v.41, p.407-431, 1996.

WHITE, R. Sexual characters of species of Diabrotica (Chrysomelidae: Coleoptera). Annals Entomological Society American, Lanham, v.70, p.168, 1977. 